\title{
6. ALIGNING LEARNING ENVIRONMENT AFFORDANCES FOR EFFECTIVE PROFESSIONAL LEARNING IN AN INNOVATIVE SENIOR SECONDARY STEM SCHOOL
}

\section{INTRODUCTION}

A shortage of graduates in science, technology, engineering and mathematics (STEM) disciplines has been reported internationally with the Australian Industry Group (2013) noting that STEM skill shortages are limiting business and opportunities to innovate and - with the growth in technology and its ubiquitous use world-wide the STEM skills shortage - will become even more evident. The report also states, "Young people in schools and universities are not acquiring the STEM skills we need for our future prosperity."

The Australian Chief Scientist Professor Ian Chubb (Commonwealth of Australia, 2012) identified that to increase suitably qualified STEM professionals a transformation in the way science and mathematics is taught in the primary and secondary year of schooling is required. But to transform science and mathematics teaching Chubb and his colleagues acknowledged an urgent need to increase the pool of inspirational teachers with extensive STEM discipline knowledge and that STEM teachers required access to high quality professional learning that incurred no individual financial burdens.

They also recognised the importance of other factors in achieving an increase in highly qualified STEM teachers including the role of school leadership and university partnerships.

Chubb's report reflected previous research including the recognition that science and mathematics education in Australian senior secondary years of schooling has experienced declining enrolments, negative students' attitudes, a shortage of qualified teachers and a curriculum that lacks relevance to contemporary life (Masters, 2006; Smith, 2003; Tytler, 2007). Such evidence called for transformation in secondary science and mathematics education and acknowledged that teachers' professional learning was central to achieving the required transformation.

In responding to such evidence Flinders University in Adelaide, South Australia in collaboration with the South Australia Department of Education and Children's Services embarked on a bold initiative to design a purpose-built mathematics and science focused school on the campus of the University. The highly innovative 
school would cater for senior secondary students only (Years 10-12) and employ cutting edge interdisciplinary curriculum developed by teachers and academics working in collaboration. Pedagogical approaches would draw on deep knowledge of effective learning processes with specific attention to inquiry-based learning.

The school day would not reflect the traditional school model of 8 periods of 40 minutes per discipline-based lesson with students divided into year levels. Rather learning would occur in extended blocks of time and students in Year 10 and 11 would be grouped together to undertake 6 interdisciplinary studies across a full year (3 per semester). The school, eventually named the Australian Science and Mathematics School (ASMS), was also unique and innovative in the design of its learning environment and the impact of this environment on the learning culture for teachers and subsequently students is the major focus of this chapter.

Marshall (2009) called for STEM education that would generate students who were "disciplinary, creative, innovative, entrepreneurial, integral, and wise" (p. 49) and this is reflected in the ASMS context statement (2013):

The ASMS will be recognised for its leadership of innovation and reform of learning and teaching in science and mathematics. The ASMS is constantly in the process of creating a learning environment for the future that will prepare young people with a passion for study in science and mathematics to be creative, critical, informed and motivated contributors responding to professional, personal and social issues.

The context statement captures once again the focus on 'creating a learning environment' to not only engage the students but to encourage students to aspire to careers in mathematics and science. The 'learning environment' was a combination of the physical learning space and the creation of a learning culture. Davies, Heath, and Bissaker (2006) noted:

The design of the building moves away from architectural-pedagogical paradigms that reinforce teacher-centred pedagogical practice and define the traditional power relationship between teacher and student. The design of the building's learning spaces is an architectural response to the desired pedagogical approaches at the school. It is designed for highly collaborative and interactive, student-directed approaches that transfer the power of adolescent social interaction into the learning environment. (p. 2)

This statement reflects that the initial design of the school was focused on generating a learning environment prioritising students' learning but teachers were also significant beneficiaries of the building's design even though this was not initially evident to them. Aspects of the building's design and its influence on the teachers' learning are also addressed in more detail hereunder. However, the focus here is on how teachers have influenced the design of the building and hence the narrative focuses on teacher-led transformative pedagogy which is a fundamental precursor to any changes in design. 
In essence the Australian and Mathematics School did not just attend to a transformation of traditional science and mathematics curriculum but addressed many factors at once, including school design, organisational elements of a school day, pedagogical models, explicit engagement with academics and the role of teachers. In supporting teachers to transition from traditional ways of teaching mathematics and science the school leaders provided a major commitment to the provision of high quality professional learning for all teachers. Those who founded the school recognised the critical nature of teachers as learner to achieve the vision of the school and stated:

The Australian Science and Mathematics School has a vision to provide a learning culture for its students that derives from a learning culture developed by its staff from their interaction with university and industry scientists and educators. (School policy statement, 2003)

\section{HIGHLY EFFECTIVE LEARNING CULTURES: RESEARCH FINDINGS}

Significant research has occurred in the previous decade to identify the feature of highly effective professional learning and learning cultures that teachers' report makes a difference to their knowledge and practice. McRae et al. (2001) promoted the concept that teachers' learning should be continuous, a daily event and situated within the workplace. They cited Retallick (1997) who made a distinction between professional development that involved attending workshops, seminars and off-site programs and site based learning involving daily opportunities to learn that are based on the current work of teachers.

Retallick (1997) argued, "What is required is not so much a change of culture in schools, but a recognition by the teaching profession that professional learning can and does take place on-the-job and in the workplace of teachers when problems and difficulties are seen as learning opportunities" (p. 23, cited in McRae et al., 2001). Fullan (2007) supported this concept and called for a distinction to be made between professional development and professional learning. He advocated that the term professional learning should replace development so that a renewed focus on the conditions for powerful learning is achieved. He stated:

Professional development as a term and as a strategy has run its course. The future of improvement, indeed of the profession itself, depends on a radical shift in how we conceive learning and the conditions in which teachers and students work. (p. 35)

He also argued that professional learning communities provided one of the best options for engaging teachers in learning as a daily event. The designers of the ASMS's physical and cultural environment reflected Fullan's concepts and the conditions in which the teachers at the ASMS worked provided rich opportunities for engaging in learning on a daily basis. 
Easton (2008) also stressed the need for schools to move beyond the paradigm of teachers being 'developed' via external professional development programs to a model whereby teachers view themselves as 'active learners' embedded in an environment that provides significant opportunities for learning. Easton contends that:

Developing is not enough. Educators must be knowledgeable and wise. They must know enough in order to change. They must change in order to get different results. They must become learners, and they must be self-developing. (p. 756)

However, to become 'self-developing' a combination of teachers' dispositions and the contextual conditions in which they work prove critical to the potential for learning and the outcomes of the learning. The ASMS recognised the interplay between the teachers and the contextual condition as fundamental to learning outcomes for the teachers and subsequent learning outcomes for students.

Desimone (2009) in her meta-analyses research on evaluating the effects of professional [learning] $]^{1}$ on teachers and students proposed that for high quality outcomes to be achieved core features must be present. She identified clarity of the professional learning content focus as a core feature. At the ASMS content foci developed and shifted over time but included a sustained focus on understanding learning and learning processes, the purposes for and characteristics of high quality interdisciplinary curriculum and cutting edge science and mathematics. The other core features of Desimone's model were more processes oriented and included a collective group of active learners participating in a coherent program conducted over time. She highlights that although the model is viewed as:

Nonrecursive [with] interactive pathways [this] does not prevent differential emphases on either the basic components (professional development, knowledge, practice, and student achievement) or the addition of moderating and mediating elements such as teacher identity, beliefs, and perceptions.

Figure 1 provides an overview of how these core features contribute to change in teachers' knowledge skills and beliefs and the subsequent influence on student learning. As noted in the figure, Desimone acknowledges that there are several underlying factors that also influence the outcomes of professional learning including teacher and student characteristics, leadership, curriculum and policy. These moderating and mediating elements were all of significant relevance to the ASMS context.

Desimone did not determine whether her model reflected school-based or external professional learning but the elements of the model reflected well the conditions evident at the ASMS. However, the design of the ASMS and the bold vision to base its innovation on teachers' professional learning is unlikely to be reflected in Desimone's meta-analyses on the effects of professional learning on the design of schools. 
As such the ASMS provided an ideal research opportunity to capture what Desimone reported as 'rare', the ability to document and acknowledge all elements, particularly those moderating and mediating influences evident in her model. She called for research that:

... provide[s] narratives, examples, and anecdotes to answer research questions directed at questioning models of teacher interactions; generating hypotheses; and describing and understanding the complexities of professional development in a specific context, how beliefs and attitudes change, and the process through which teachers change their instruction. (p. 190)
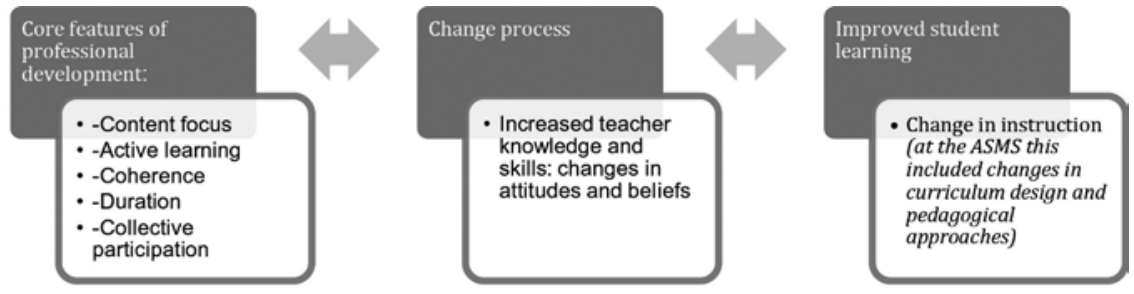

Influenced by context such as teacher and student characteristics, curriculum, school leadership and policy by context such development

Figure 1. Desimone's (2009, p. 185) conceptual framework for studying the effects of professional development on teachers and students

This research was designed to capture what Desimone acknowledged as an ongoing and important gap in the research literature on powerful professional learning for teachers.

\section{THE RESEARCH PROCESS}

The research was conducted over a period of seven years and grounded theory methods were used to answer research questions about what supported and sustained teachers' learning in this innovative context and the outcomes of teachers' learning for teachers, students and the school. To achieve an authentic account of the teachers' lived experiences I positioned myself as an insider-researcher working intensely and thoughtfully with staff at the ASMS.

The analysis and interpretation of a range of data (including interviews, observations and open-ended surveys) collected over an extended period of time supported the development an in depth understanding of the interactions between contextual conditions, organisational elements and relationships factors that provided a context for and enabled teachers' professional learning. 
An explanatory model of professional learning that reflected the complexity of the many elements alluded to by Desimone but not able to be captured in her research was developed as an outcome of the theorising process. The model identified the importance of alignments between teachers' capacities, characteristics and sense of personal agency and specific contextual conditions, organisational elements and relationship factors. A full account of the model's development can be located in Bissaker (2010); however, this chapter focuses more specifically on the influence of the physical environment on teachers' learning and the culture of learning in general. There was clear evidence from the research that many 'contextual' factors beyond the building's design including the school's philosophy and vision, the leadership, colleagues, interdisciplinary curriculum writing teams and the school-university partnership were all instrumental in generating a powerful learning culture.

The research reported in the original thesis on which this chapter is based (Bissaker, 2010) captured the complex interactions between contextual conditions, organisational elements and relationship factors in generating an environment for daily high quality professional learning at the ASMS. In addition, it acknowledged the dispositions of teachers and their sense of personal agency as a fourth element of significance in the professional learning model.

The model captured the interactive nature between these four areas noting the importance of the many incidental and intentional learning opportunities generated through the alignment of teachers' learning interests and needs and the conditions for learning present as an outcome of the physical and cultural environment of the school. These alignments were many and varied but fundamental to high quality daily professional learning for all teachers at the ASMS. The alignments were ultimately identified as affordances. ${ }^{2}$

\section{AFFORDANCES}

The term affordance is used as a noun to identify the relational aspects of the actor and their environment; in this research being the teachers and the school's design and organisation. James Gibson (1977, cited in Wenger, 1998), initially used the term to define the many possibilities of action when an actor interacts with an environment. Gibson provides the examples of a human coming together with a set of stairs as providing an affordance for climbing, similarly the claws of a squirrel and tree also provide an affordance for attaining a goal.

An affordance is generated when the environmental conditions match well with the actor using the environment to achieve a goal. The concept of affordance has generally been associated with the properties of an evironment or object in the environment. Initially this may be thought of as the physical enivornment but in this research it became evident that the cultural environment created through the schools' context and organisational elements also acted as affordances for learning. McGrenere and Ho (2000) in an attempt to clarify the definition of an affordance highlighted that: 
Gibson describes the environment as being composed of nested objects and he describes the nesting of information that specifies affordances but he never specifically uses the term nested affordances. (p. 2)

McGrenere and Ho's use of the terminology 'nested affordances' to describe connections between objects and information fits well with the outcomes of the research on affordances for learning at the ASMS. For example, although the design of the school clearly acted as an affordance for learning it might have also worked against the learning of those teachers who felt anxious about their teaching practices being consistently on 'display'.

For the physical environment to act as an affordances for the majority of teachers in the school a 'nested' affordance associated with the cultural and organisational enviroments also needed to be in place. In this sense, attention to the generation of building trust and respect between teachers through providing time and space for teachers to work in interdisciplinary curriculum writing teams and team teaching situations were acknowledge as affordances for teachers' learning.

Another important understanding of the affordance concept, and of particular relevance for this research project was Gibson's notion that an affordance can exist independent of the individual's ability to perceive this possibility (McGrenere \& Ho, 2000). This concepts suggests an individual may not acknowledge a specific affordance as being of influence to their attainment of goals. They may either see themselves as in control of such outcomes or fail to acknowledged the 'nested' nature of affordances that contribute to achieving desired outcomes.

For individuals working in enviroments much reflection is required before they may start to conceive of the many affordances that have contributed to the achiveing of preferred goals. This research provided many opportunities for teachers to consider what influenced their learning, in additional extensive observations were made of teachers teaching and learning in the ASMS environment. This data provided ongoing opportunity over a seven year period for developing a deep understanding of the many obvious and less obvious affordances for teachers' learing.

Affordances for learning at the ASMS were varied and in abundance. They were at the very heart of processes that allowed teachers to learn individually and collectively. However, as Wenger (1998) said, "one can produce affordances for the negotiation of meaning, but not meaning itself" (p. 229). Wenger also claimed, "Learning is first and foremost the ability to negotiate new meanings: it involves our whole person in a dynamic interplay of participation and reification." (p. 229). In essence Wenger identified that "learning is a matter of alignment" (p. 228) which depends on learners connecting their inner understandings and perspectives with learning opportunities presented to them preferably in ways that direct energies to the common purpose of the learner and the organisation. This connects well with Gibson's view that an affordance reflects mutuality between the actor and environment.

Figure 2 provides an overview of the interaction between the enabling contextual conditions and alingment for learning that is created when these fit well with teachers' 
individual goals, beliefs, capacity and sense of personal agency. The very diverse nature of teachers as individuals immediately illuminates the need for diversity within the enabling conditions as well and examples of these alignment will shared in the outcomes section of this chapter.

Figure 2 also highlights how the outcomes of the teachers' learning influenced both the enabling conditions and their individual dispositions. In this sense teachers were shaped by what they brought to the learning environment and by the nature of the learning environment but they also helped to shape the growth of the environment and themselves. This iterative and generative cycle proved critical in sustaining a rich learning culture over time.

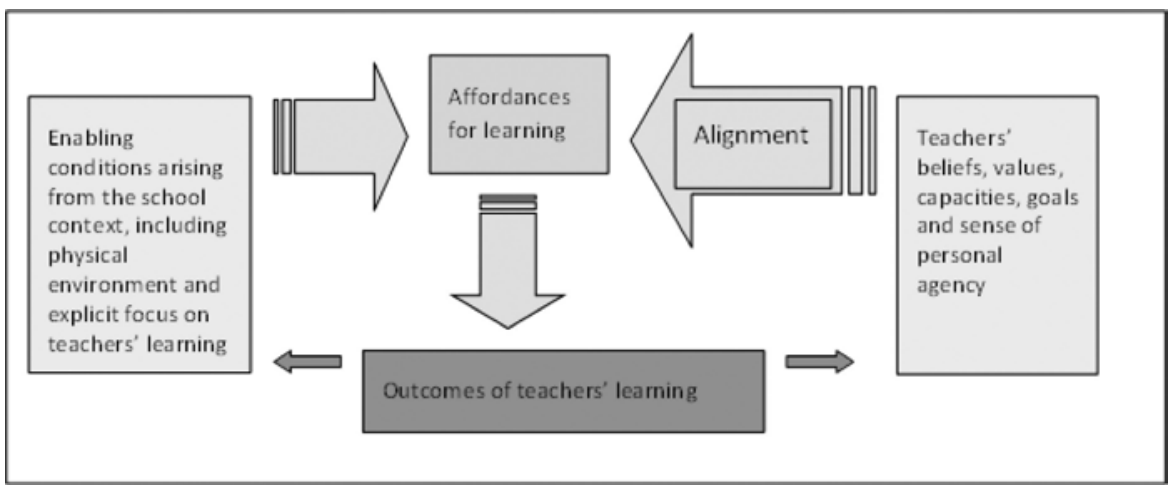

Figure 2. Factors that contribute to creating affordances for teachers'learning

\section{THE SCHOOL'S ENVIROMENT AND ITS IMPACT ON PROFESSIONAL LEARNING}

"The opening day of the year with the balloons and everything was such a surprise to me ... I mean for the past 10 years I have been walking into schools and commiserating with the students about being back at school ... it's a different feel altogether here, you want to be here" ASMS teacher reflecting on the first day in the school's second year of operation.

"There's no boundaries here - in the building, or to our learning" Student quoted in the Evaluation of the Higher Education Innovation Programme at the ASMS. Australian Council for Education Research, May 2005.

These reflections from an ASMS teacher and student indicate the school provided a learning and cultural environment that was highly valued by the key stakeholders. Both make explicit reference to the physical elements of the learning space, some generated by the building design the other (balloons) an element added to the space 
by the people using the space. The following section provides an overview of the learning space and examples of how it was used.

The 4000 square metre building was constructed over two levels. Figures 3 and 4 are basic floor plans of the building and these have been included to gain a sense of the difference in architecture from more traditional schools. The building featured large open-space teaching areas called learning commons (LC). The 9 LC were approximately 160 square metres in size. Every LC provided workstations and storage lockers for approximately 50 students. The building was designed to accommodate a maximum of 450 students but in flexible ways.

The LC provided a "home space" for groups of students. One teacher supervised the groups of students, between 10 and 15, and up to three groups would share one LC. The groups were known as tutor groups and would meet daily. The openness of the LC allowed for staff and students from a number of tutor groups to interact and support each other. The LC also provided the key teaching areas and 3-4 different teaching and learning groups might be in action at any one time, or alternatively, 2-3 teachers within one LC may manage one large group of students.

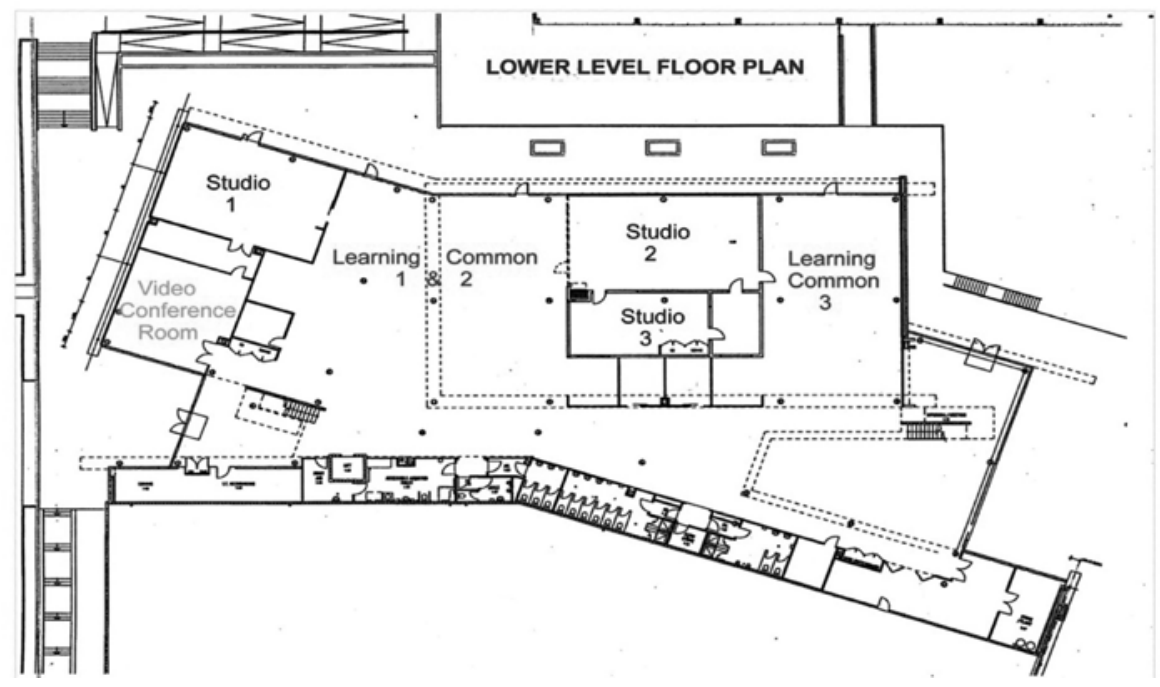

Figure 3. Lower level floor plan

(ASMS school planning archives, 2003)

The furniture provided in the LC allowed for lecture style seating, chair and table layout, larger tables for group work and combinations of all three. Electronic whiteboards, data projectors, overheads and display screens were available in two strategic fixed locations with $30+$ computers and mobile teaching platforms 
(which provided access to DVD/Video players and large flat screen televisions) also available in most LC.

The building also incorporated a series of learning studios as replacements for the more traditional school laboratories. The studios, all leading off the learning commons, were divided by transparent glass walls and sliding doors. The intended effect was to create a learning space where all student and teacher action could be readily observed and where there was a sense of connection between locations. The studios were designed to cross the boundaries between traditional disciplines and promote an interdisciplinary platform for learning.

There were nine learning studios with varying names including Human Performance, Video Production, Physical Sciences, Applied Technology, Life Sciences, Environmental Science and Mathematics. No one teacher had responsibility for any particular learning studio as they were used when relevant to the learning needs of students.

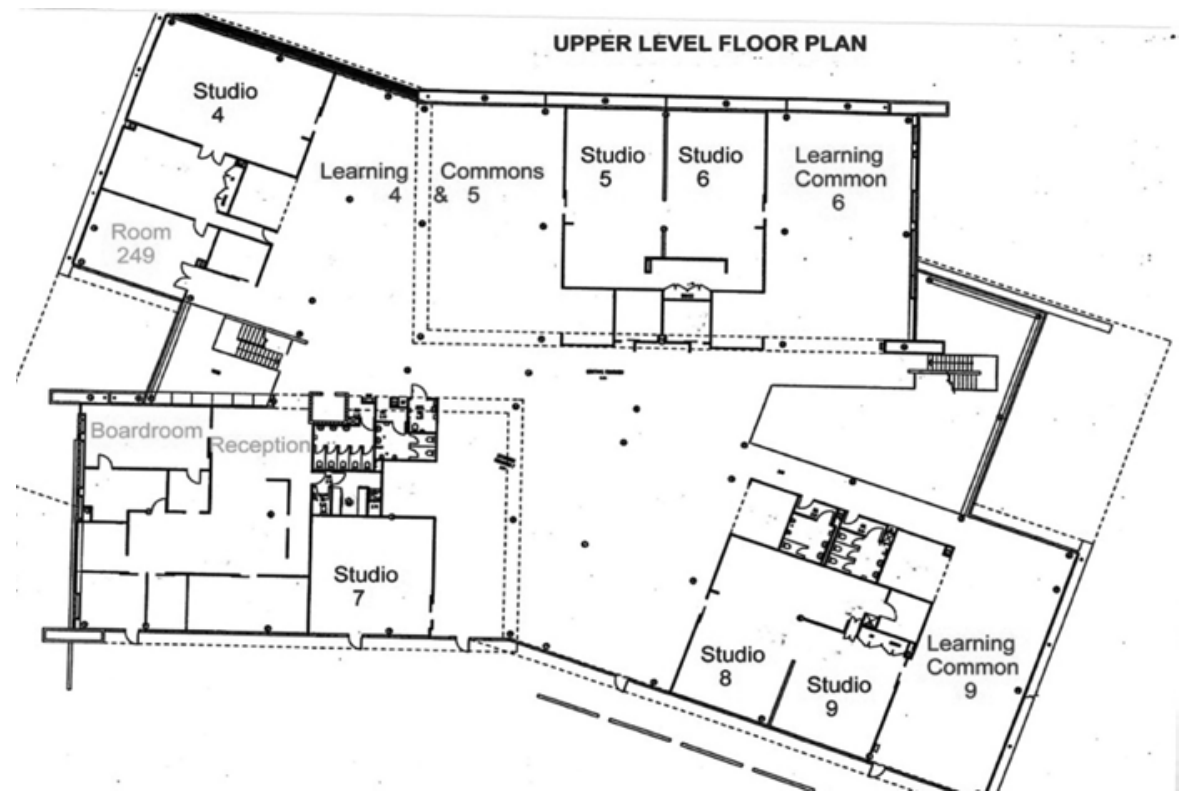

Figure 4. Upper level floor plan

(ASMS school planning archives, 2003)

Another key feature of the building was the Central Common. The architectural brief (ASMS School Planning Archive, 2003), said "the central internal space links all the functional spaces to promote a sense of community within the school ... it provides a strong visual identity with an impressive two-storey space with raking ceilings and roof lights and larger areas of glass, ... and a flexible gathering space for 250 ” (p. 14). 
The space has been used for a diverse range of functions including many conferences. These conferences attended by local, national and international educators and professionals are conducted in the same space as students attending classes. The outcome of adults and students working together in time and space contributed further to the "learning culture" of the school. The building design was fundamental to promoting teachers' and students' learning and to the sense of a dynamic and generative learning culture.

To extend the notion of students and teachers working and learning together the building did not provide staff preparation or faculty offices. Teachers' working spaces were distributed throughout the building and located off the learning commons. Two to three teachers shared these spaces. Teachers were constantly visible to students as they engaged in preparation, research, marking, discussion with colleagues and so forth. During teachers' non-instructional time they were in a position to observe and hear the learning and teaching occurring in the learning commons adjacent to them which provided an obvious affordance to teachers' incidental learning.

The affordance specifically linked with the learning environment at ASMS was that of physical proximity and its influence on teachers' learning is discussed in more details shortly.

The flexibility of the furnishing within the learning spaces provided numerous opportunities for teachers and students to create specific and varied learning environments. The building provided quiet and withdrawn learning spaces for 1-2 people through to larger open spaces that could cater for over 300 people attending a key-note lecture. Such flexibility allowed for many different teaching and learning configurations from one teacher working with individuals and small groups through to another lecturing to a group of $200+$ students.

It was common to walk through the building and not be aware of which teachers were responsible for which group of students. There were always teachers "on the floor" in the learning commons and teachers working in the teacher-area alcoves. Teachers often worked in more traditional ways as well, for example, leading a group of students as they introduced new concepts or assignments. Other teachers in the same vicinity not specifically engaged with students were always available if students needed clarification about anything.

Students also made interesting use of the environment. They could be found in larger classes in the LC, working in smaller groups in glass-walled rooms located off the learning commons, or studying individually on the long flat benches that were strategically located throughout the building. At times students appeared to be "resting" or opting out of more formal learning processes but it often came as a surprise to visitors and close observers that such students were actually engaged in learning and had merely chosen a more relaxed way for the body to do this.

The extensive use of glass and open walled spaces significantly reduced the wall space available for displaying student work or teaching resources. However, the material mounted on walls was strategically selected for its explicit focus on learning and to remind students what the school was all about. Posters featured 
learners such Einstein commenting, "It's not that I am so smart it just that I stay with problems longer"

The differences between the learning space of the ASMS and more traditional senior secondary schools were clearly evident. The open design was complemented by the significant availability of current technology including computers, smart boards, display monitors, mobile platforms incorporating DVD players, large digital televisions and sound systems. The school had a wireless network and many students brought their personal laptop as their primary learning resource.

The students' work was kept in e-portfolios instead of lockers and could be accessed by parents through the school's portal system. Students' preferred technologies of mobile phones and ipods were incorporated, rather than excluded from the learning environment.

There is much evidence that the ASMS reflected the high-quality learning environment that Malaguzzi (cited in Palsha, 2002) called for in Reggio preschools. Gandini (2002) described Reggio environments as "an amiable space", an environment that:

conveys the message that this is a place where adults have thought about the quality and the instructive power of the space. The layout of the physical space is welcoming and fosters encounters, communication and relationships. The arrangement of structures, objects, and activities encourages choices, problem solving and discoveries in the process of learning. (p. 17)

Gandini's description of Reggio environments sat well with what was found at the ASMS and there was no doubt that the learning space reflected Malaguzzi's ideas of an environment that amplifies learning opportunities and outcomes for both students and teachers.

Alignment of the learning environment affordances for teachers' learning. The design of the learning spaces at the ASMS clearly promoted physical proximity and connectedness among the learning community. Physical proximity was identified as an affordance for learning in the previous section but the flexibility and interactive nature of the building design were also fundamental to both intentional and incidental learning for students, teachers and others who were visiting the school.

Teachers in the school made the following observations of how the design of the building acted as an affordance for their learning:

I think this building has been one of the biggest contributors to my learning purely because you can't escape ... it's the open nature, I can just sit at my desk and someone will walk past and I'll think what's he doing ... oh that is interesting ... I never thought about doing it like that ... even if it's just a small idea or activity.

I saw "James" teaching this unit I had designed the other day and was so surprised as I had never considered introducing it the way he did, I just sat back and watched and listened and it really opened my eyes to a new way of doing it. 
It's the environment ... I haven't really invited other teachers into my classroom in the past ... so even though I had good relationships with them we didn't look towards team teaching and really working together ... it just seems the natural thing to do here.

It's often the case that you attend a conference where someone will say that they have something really interesting in their class and they describe what they have done. At the time you think that this is a marvellous idea and that you will go and try it yourself. You return to your school and lock yourself away in a little box of a room and very little changes. Here, because of the open nature of the building and the collaboration that occurs it is very easy to see others have done those marvellous things and to be encouraged to try them for yourself.

It is interesting to note that the teachers' comments while focusing on the environment as an affording factor in their learning, all made links to learning from another person in the environment, not from the environment itself. The role of teacher colleagues and students in the environment were identified by teachers as affordances for learning but it is important to note they may not have 'seen' these colleagues or students if they were isolated more traditional classrooms, staffrooms or faculty preparation areas.

A common complaint from teachers in more traditionally designed schools is the lack of opportunity to observe colleagues in action. The opportunity to spend time watching others teach is acknowledged by teachers and researchers alike (Easton, 2004; Darling-Hammond \& Sykes, 1999; Guskey, 2000; Hawley \& Valli, 1999; OCED, 2009) as a powerful form of professional learning which in traditional schools is often hard to embed within daily life. Space, time and costs often restrict teachers' opportunities to learn from colleagues in action. At the ASMS, teachers were afforded the opportunity to observe their colleagues while they were working.

Many commented on the small things they noticed others doing while they were teaching. For example, one teacher said, "I noticed [Larry] using this really interesting picture in a maths class so when I finished teaching ... over lunch he told me all about it." There were numerous examples of this, all made possible by the design of the building although as Wenger identified the building provided the opportunity for the negotiation of new meaning but the teachers were in charge of what they noticed within the environment and how they made meaning from this (Moon, 1999).

Teachers in their non-instructional periods were sitting adjacent to classes in action and therefore provided with ongoing opportunities to 'notice' what others were doing, both students and teachers. In general, the 'noticing' occurred when something was relevant or of interest to the teacher. Teachers responded in various ways, for example, by thinking, "that's interesting ... I might talk with [Mike] more about that later." The noticing triggered more intentional plans from an incidental beginning. 
Alternatively, they responded, "that's interesting ... I never knew that," with the new information stored (successfully or unsuccessfully), but with no further plan to follow up on that learning with the colleague. Such possibilities were well supported by the design of the environment but also demanded the teachers have a learning 'headset'. Teachers' personal characteristics and capacities influenced how they engaged with the environment and therefore learning was afforded by a combination of physical proximity and teacher-located factors such as openness, motivation, purposeful listening and so forth.

Teacher colleagues and students were critical elements in the environment that added to the quality of teachers' learning. However, there were also features of the environment that presented opportunities for learning in their own right. The ASMS was a technology rich environment and this also influenced teachers' learning.

The following teacher reflection highlighted that the availability of technology influenced both content and pedagogical knowledge learning:

Its definitely the fact that we're using computers extensively that's causing this [new learning], it means that we both write the uses of computers into our materials and we also use computers for just about everything, our databases, our intranet and so on. There's a fair bit of learning going on there for teachers and students ...

Learning about, and how to use, the available technology was often planned for. Teachers engaged in professional learning sessions run by colleagues or an outside facilitator but it was through the ready availability of the technology that teachers had the opportunity to 'practise' new skills and 'play around' with options before including such ideas in their teaching. The newness and reliability of the system encouraged teachers to make extensive use of technology as a tool for their own and student learning.

In addition to the extensive availability of technology to support learning, the ASMS was located within a university. This provided sustained access to the university laboratories (both indoors and outdoors) and a library full of texts and references on a range of disciplines and pedagogical research. There was also the opportunity to attend university events and more importantly meet with university partners over morning tea breaks without the need to drive long distances after work hours or taking extensive time away from the school.

The school was designed for adult learning both within the school walls and in its location on a university campus. Many staff ultimately enrolled in university courses based on its physical proximity which added a structured and specific support for teachers' learning.

In essence, the physical nature of the learning space with its rich ICT resourcing and location on a university's ground provided tangible affordances for teachers' learning. However, the responses from teachers about what supported their learning identified a range of other less obvious affordances which linked more specifically to the cultural environment of the school. These affordances included the school's 
vision and innovative organisation, interdisciplinary curriculum writing teams, supportive leadership and an explicit professional learning strategy which engaged all staff in group research projects focused on pedagogical practices.

The outcomes of teachers' learning for teachers, students and the school as a learning organisation were thought of as:

... a combination of the environment and the vision of the leaders which has been adopted and re-created by the teachers so that the ASMS emerged as a cultural environment ... where everyone leads learning. (ASMS teacher)

This teacher's reflection ascertained that the vision of the school was adopted and re-created by teachers which resulted in a generative learning organisation that represented much of what has been called for in the research literature, including schools that prioritised time for teachers' learning, problematic discourses, leadership for learning (by all) and engagement with experts from the broader community (Caldwell, 2008; Darling-Hammond \& Richardson, 2009; Fullan, 2001, 2007; Hargreaves, 2003; Pace Marshall, 2006; Postholm, 2012; Timperly et al., 2007).

As this teacher and others in the school and the broader research community acknowledged interactions between and alignment of affordances within the learning environment are pivotal to the quality of professional learning outcomes. And these outcomes were of influence to not only teachers but the school's students, the school as a learning organisation and the broader education community.

Table 1 provides an overview of observations made by the ASMS's teachers, students, leaders and professional partners noting the influence of teachers' learning on the outcomes for other stakeholders. Interpretations of affordances that have supported these outcomes are also presented in the table. Affordances were of a contextual, organisational and relational nature but with sustained interactions between the different affordances.

These interactions capture the challenges of trying to isolate specific factors that make a difference to the quality and outcomes of teachers' learning (as often noted in models of change, see Guskey, 2000; Desimone, 2009). Rather they highlight it is the richness of the school's vision and its enactment as a learning organisation that generated rich and varied learning outcomes for many beyond the teachers.

The research determined that teachers brought existing beliefs and practices to the ASMS but through incidental and intentional learning these beliefs and practices were expanded and often changed. The design of the school created a learning environment in which affordances for learning were rich and varied.

The opportunity for teachers to learn from both intentional processes and incidental opportunities contributed to teachers' knowledge of effective pedagogy including learning and learning processes, new science and mathematics content, effective curriculum design and authentic assessment processes.

They were open to challenges and recognised their roles as learners in achieving the vision of the school. There were varied outcomes for different teachers and this appeared to be generated by the different levels of alignment between individual 
Table 1. Learning outcomes as reported by ASMS stakeholders - Conclusion

\begin{tabular}{|c|c|c|}
\hline Source & Quote & Affordances \\
\hline Teacher & $\begin{array}{l}\text { Being on display, to other ASMS teachers and the stream } \\
\text { of visitors ... I have had more professional interaction } \\
\text { with science teachers; something I did little of in my } \\
\text { previous school. I have had to spend an immense amount } \\
\text { of time planning teaching sessions, more time developing } \\
\text { resources online and taking more risks in curriculum } \\
\text { delivery. The assessment of tasks has changed through } \\
\text { the greater use of rubrics. Teaching science content and } \\
\text { concepts has been a huge change. }\end{array}$ & $\begin{array}{l}\text { Physical } \\
\text { proximity } \\
\text { Colleagues } \\
\text { Explicit PL } \\
\text { strategy }\end{array}$ \\
\hline Teacher & $\begin{array}{l}\text { The most significant learning has occurred in a } \\
\text { triumvirate manner firstly, that based upon the collegial } \\
\text { atmosphere of the school, the ability to learn from } \\
\text { colleagues both in a semi-formal and informal manner; } \\
\text { secondly, the committed stance made by the leadership of } \\
\text { the school towards professional development and the third } \\
\text { aspect being as a graduate teacher the ability to plan, } \\
\text { programme, teach and evaluate. I feel that I have become } \\
\text { both a more knowledgeable and effective teacher and this } \\
\text { has been supported by everything that happens in this } \\
\text { school. }\end{array}$ & $\begin{array}{l}\text { Physical } \\
\text { proximity } \\
\text { Colleagues } \\
\text { Leadership } \\
\text { School vision \& } \\
\text { culture } \\
\text { Sense of } \\
\text { personal agency }\end{array}$ \\
\hline Teacher & $\begin{array}{l}\text { The close collaboration across the disciplines has meant } \\
\text { less skepticism about team teaching. }\end{array}$ & $\begin{array}{l}\text { Colleagues } \\
\text { Interdisciplinary } \\
\text { curriculum } \\
\text { writing teams }\end{array}$ \\
\hline Teacher & $\begin{array}{l}\text { Perhaps it is just repetition, but collegial support, the } \\
\text { feeling of being part of a dynamic developing place that } \\
\text { gives me the opportunity to try new things and values my } \\
\text { efforts has been significant to my learning. }\end{array}$ & $\begin{array}{l}\text { Colleagues } \\
\text { School vision \& } \\
\text { culture }\end{array}$ \\
\hline Student & $\begin{array}{l}\text {... they're like a colleague; you can talk to them about } \\
\text { stuff. It's not like 'them' and 'us' ... the environment is } \\
\text { more relaxed. }\end{array}$ & $\begin{array}{l}\text { School vision } \\
\text { Physical } \\
\text { proximity }\end{array}$ \\
\hline Student & $\begin{array}{l}\text { At my old school I had some really bad teachers who I just } \\
\text { didn't want to learn from, like, I wasn't interested in what } \\
\text { they had to say. But here, like, you notice that a lot of the } \\
\text { teachers have stuff that is worthwhile to teach }\end{array}$ & $\begin{array}{l}\text { Explicit PL } \\
\text { strategy } \\
\text { Interdisciplinary } \\
\text { curriculum } \\
\text { writing teams }\end{array}$ \\
\hline Leadership & $\begin{array}{l}\text { A great positive about leading in this place is people's } \\
\text { level of commitment; a real obvious example is that } \\
\text { teachers are hardly ever away ... it's the lowest level of } \\
\text { teacher absenteeism I have experienced in any school ... }\end{array}$ & $\begin{array}{l}\text { School vision } \\
\text { and culture } \\
\text { Distributed } \\
\text { leadership }\end{array}$ \\
\hline
\end{tabular}


Table 1. (Continued)

\begin{tabular}{lll}
\hline Source & Quote & Affordances \\
\hline Leadership & $\begin{array}{l}\text { There are so many tangible things, like teachers leading } \\
\text { innovation in curriculum but they are easy to see. It's the }\end{array}$ & $\begin{array}{l}\text { School vision } \\
\text { and culture }\end{array}$ \\
& $\begin{array}{l}\text { deeper levels that are harder to capture. I think we have } \\
\text { made significant contributions to policy level discussion }\end{array}$ & $\begin{array}{l}\text { Interdisciplinary } \\
\text { curriculum }\end{array}$ \\
& and our staff's involvement in that at a systems level has & writing teams \\
been critical. How do you actually quantify that we've & Physical \\
had a significant effect on system level policy but we have & proximity \\
certainly developed a capacity amongst teachers in our & \\
& school for them to engage in conversations about learning \\
& and about learning environments that need to be created & \\
& to support raising opportunity, increasing participation & \\
& and engagement. & \\
\end{tabular}

teachers and the learning environment as described in Figure 2. Recognition of these variations in an important consideration for school leaders as it provides evidence that both individual teacher characteristics and sense of personal agency together with the learning environment in which they work/teach influence learning outcomes.

The learning environment will be experienced in different ways and the task is to create a rich and diverse learning environment that provides multiple opportunities and processes for learning. This concept can also be translated to learning for students as was the case at the ASMS.

As reported earlier, the students saw no boundaries to their learning and recognised learning as a partnership between themselves and the cultural and physical environment. The cultural and physical environment generated at the ASMS led one teacher to comment:

I have made an escape from a raft of traditional paradigms about schooling as a process. I have been liberated from the school:classroom:teacher: class:subject: grades:reports constructs. I don't see schooling anymore defined by these confining delineations.

Although the ASMS is a unique school, there is much to be learned from those willing to redefine traditional paradigms of schooling and it would be wise not to dismiss the outcomes of this research due to the unique nature of the school. One particular outcome clearly worthy of consideration by those interested in 'reenvisioning' not just science and mathematics education but all schooling was the role of the learning space.

The ASMS learning space was reflective of Greenman's (1988) view:

An environment is a living, changing system. More than physical space, it includes the way time is structured and the roles we are expected to play. 
It conditions how we feel, think and behave; and it dramatically affects the quality of our lives. The environment either works for us or against us as we conduct our lives. (p. 5)

The ASMS was an environment that 'worked' for many teachers, students and other educators and although it represented a large economic and human resources investment the outcomes proved insightful and important in understanding what is possible for schooling in the senior secondary years.

The following comment from one visitor to the school in April 2009, seven years on from its opening might be valuable advice on using the outcomes of the research too;

This school brings real meaning to, 'if we want to shape the future, we must create it'.

\section{NOTES}

1 Desimone uses the term professional development in her paper but for the purposes of this paper I have replaced this with professional learning as it more effectively captures the learning culture at the centre of this chapter.

2 An affordance is generated when environmental conditions enable the actors using the environment to achieve a desired goal.

\section{REFERENCES}

Australian Council of Learned Academies (ACOLA). (2013). Securing Australia's future: STEM country comparisons. Australia: Author.

Australian Industry Group. (2013). Lifting our science, technology, engineering and maths (STEM) skills. Australia: Author.

Australian Science and Mathematics School. (2003). School planning archives document. (Unpublished).

Australian Science and Mathematics School. (2013). Context statement. Retrieved from http://www.asms.sa.edu.au/wp-content/uploads/2013/07/School-Context-Statement-2013.pdf

Bissaker, K. (2010). The processes and outcomes of teachers' professional learning in an innovative school: The construction of an explanatory model (Unpublished doctoral dissertation). Retrieved from http://trove.nla.gov.au/work/38783221? versionId $=51498682$

Caldwell, B. (2008). Raising the stakes: From improvement to transformation in the reform of school. London, England: Routledge

Darling-Hammond, L., \& Richardson, N. (2009). Teacher learning: What matters? Educational Leadership, 66(5), 46-55.

Darling-Hammond, L., \& Sykes, G. (1999). Teaching as the learning profession: Handbook of theory and practice. San Francisco, CA: Jossey-Bass.

Davies, J., Heath, J., \& Bissaker, K. (2006). Re-thinking schooling: Reflections from the Australian science and mathematics school. Proceedings from the Educational Research Association Conference, Singapore.

Desimone, L. (2009). Improving impact studies of teachers' professional development: Towards better conceptualizations and measures. Educational Researcher, 38, 181-199.

Easton, L. B. (Ed.). (2004, June). Powerful designs for professional learning. Fairfield, OH: NSDC.

Easton, L. B. (2008). From professional development to professional learning. National Staff Development Journal, 89(10), 755-761.

Fullan, M. G. (2001). Leading in a culture of change. San Francisco, CA: Jossey-Bass. 
Fullan, M. G. (2007). The new meaning of educational change (4th ed.). London, England: Cassell.

Gandini, L. (2002). The story and foundations of the Reggio Emilia approach. In V. Fu, A. Stremmel, \& L. Hill (Eds.), Teaching and learning: Collaborative exploration of the Reggio Emilia approach. Upper Saddle River, NJ: Merrill Prentice Hall.

Greenman, J. (1988). Caring spaces, leaning spaces: Children's environments that work. Redmond, WA: Exchange Press.

Guskey, T. R. (2000). Evaluating professional development. Thousand Oaks CA: Corwin Press.

Hargreaves, A. (2003). Teaching in the knowledge society: Education in the age of insecurity. Philadelphia, PA: Open University Press.

Hawley W. D., \& Valli, L. (1999). The essentials of professional development: a new consensus. In L. Darling-Hammond \& G. Sykes (Eds.), Teaching as the learning profession: Handbook of theory and practice. San Francisco, CA: Jossey-Bass.

Masters, G. (2006). Boosting science learning - What will it take? Paper presented at the ACER Conference 2006. Retrieved February 18, 2008, http://research.acer.edu.au/research conference 2006/4

McGrenere, J., \& Ho, W. (2000). Affordances: Clarifying and evolving a concept. Proceedings from Graphic Interaction Conference, Montreal, QC. Retrieved May 17, 2014, from http://www.graphicsinterface.org/proceedings/2000/177/

McRae, D., Ainsworth, G., Groves, R., Rowland, M., \& Zbar, V. (2001). PD 2000 - Australia: A national mapping of teacher professional development. Canberra, Australia: Commonwealth Department of Education, Training and Youth Affairs.

Moon, J. (1999). Reflection in learning and professional development: Theory and practice. London, England: Kogan Page.

OECD. (2009). Creating effective teaching and learning environments: First results from TALIS. Report for the Organisation for Economic Co-operation and Development Centre for Educational Research and Innovation. Retrieved June 8, 2009, from http://www.oecd.org/document/54/ 0,3343,en_2649_39263231_42980662_1_1_1_1,00.html

Marshall, S. (2006). The power to transform: Leadership that brings learning and schooling to life. San Fransico, CA: Jossey-Bass.

Palsha, S. (2002). An outstanding education for ALL children: Learning from Reggio Emilia's approach to inclusion. In V. Fu, A. Stremmel, \& L. Hill (Eds.), Teaching and learning: Collaborative exploration of the Reggio Emilia approach. Upper Saddle River, NJ: Merrill Prentice Hall.

Postholm, M. b. (2012) Teachers' professional development: A theoretical review. Educational Research, 54(4), 405-429. Retrieved November 3, 2012, from http://dx.doi.org/10.1080/00131881.2012.734725

Smith, D. (2003). Learning, teaching and innovation: A review of literature on facilitating innovation in students, schools and teacher education with particular emphasis on mathematics, science and technology. Report to the Commonwealth Department of Education, Science and Technology. Canberra. Retrieved April 17, 2004, from http://www.dest.gov.au/NR/rdonlyres/ D4511076-4200-4257-8B47-B78E4A78A38A/1660/innovation.pdf

Timperley,H., Wilson, A., Barrar,H., \& Fung, I.(2007). Teacherprofessionallearning and development: Best evidence synthesis iteration. Retrieved January 17, 2008, from http://www.educationcounts.govt.nz/ publications/series/2515/15341

Tytler, R. (2007). Australian education review: Re-imagining science education: Engaging students in science for Australia's future. Camberwell, Australia: Australian Council for Educational Research Press.

Wenger, E. (1998). Communities of practice: Learning, meaning and identity. Cambridge, England: Cambridge University Press.

\section{Kerry Bissaker}

Flinders University of South Australia 